\title{
A Significant Enhance of Impact Strength with Thermal Annealing in High Density Polyethylene
}

\author{
María L. Cerrada, ${ }^{\dagger}$ Rosario Benavente, and Carmen A. Sierra ${ }^{*}$ \\ Instituto de Ciencia y Tecnología de Polimeros (CSIC); Juan de la Cierva 3, 28006 Madrid, Spain \\ ${ }^{*}$ Repsol-YPF Área Operativa Quimica (LATD), Embajadores 183, 28045 Madrid, Spain
}

(Received October 10, 2000; Accepted January 5, 2001)

\begin{abstract}
Different structural, thermal, mechanical and viscoelastic characteristics established in an annealed commercial high density polyethylene (HDPE) are described and compared to those in the as molded sample. The main features found in the annealed specimen are a significant improvement in the impact strength and a greater intensity of the $\beta$ relaxation process. In addition, a loss of some low molecular weight products is also found joined to a slight perfection in the crystalline phase. The causes for those features are discussed.

KEY WORDS High Density Polyethylene / Annealing / Impact Strength / Crazes / Relaxation Processes / Crystalline Regions /
\end{abstract}

Polymers are not the only material used for packaging, though, in many cases they are replacing the less convenient or more expensive classical ones such as metal, glass and wood. ${ }^{1}$ In other cases, polymers enable reduction of consumption of such classical materials where their use is indispensable and polymers confer refinement of these packaging materials. This applies, $e$. g., to laminated aluminum foils or laminated paper that can be welded to produce large, easily shaped and airtight packages in a more economical way than in the traditional cannery tins or bottles. The large variety of physical and chemical properties of polymers extends their applicability as far as the protective function of packages is concerned.

In particular, polyethylene is a very important material used in the packaging industry. One of the most important applications of high density polyethylene (HDPE) is the production of different industrial containers of up to $2000 \mathrm{~L}$ capacity for the transportation and storage of liquid chemicals and oils. Such containers are processed by blow extrusion molding. ${ }^{2}$ There are several types of containers depending upon their capacity. Some common examples are the Jerrycan and L-Ring types. The former one incorporates a handle and shows a capacity lower than $50 \mathrm{~L}$ whereas the L-Ring type consists in a cylindrical deposit with a capacity of $220 \mathrm{~L}$. All these different categories of containers have to be rigorously tested and go beyond a very severe homologation tests in order to be used for transporting and storing of those mentioned dangerous substances. One of the critical testing is the impact resistance or drop test of these containers filled with a standard liquid up to $95 \%$ being this experiment performed at different heights and temperatures.

A traditional measure of the fracture behavior of a material is the Izod or Charpy impact tests. Such tests are performed at laboratory scale on specimens molded by compression being their results correlated to those attained from the drop test. The principle of both methods is to strike a small bar of polymer with a heavy pendu- lum swing. In the Izod test the bar is held vertically by gripping one end in a vice and the other free end is struck by the pendulum. In the Charpy test the bar is supported near its ends in a horizontal plane and struck either by a single pronged or two-pronged hammer so as to simulate a rapid three-point or four point bend test respectively. It is customary to introduce a central notch into the specimen. The impact resistance of a given polymer depends upon either morphological aspects of the material utilized, such as crystalline content, molecular weight, and its distribution or the processing conditions.

An annealing process is often applied to improve the dimensional stability of the final article. During such a process material is exposed to a temperature lower than that used for transformation. The annealing provokes considerable relaxation of the tensions introduced by processing and the material thus acquires a higher stability. Annealing at $100^{\circ} \mathrm{C}$ for $500 \mathrm{~h}$ has caused a striking enhance in the impact resistance in a commercial HDPE which is used in the manufacturing of containers utilized for transportation and storage of oils. Annealing generally provokes an increase of crystallinity and larger crystallites. ${ }^{3}$ At higher degrees of crystallinity, the impact strength commonly decreases. Superimposed on the degree of crystallinity is the effect of the crystallite morphology. As spherulites become larger and more prominent, the impact strength also diminishes. The aim of the current work is to get insight the unusual and interesting enhance of the impact strength attained after annealing. To analyze changes on the structure and the subsequent variation of the properties exhibited several techniques have been used including: X-Ray diffraction, Raman spectroscopy, scanning electronic microscopy, differential scanning calorimetry, thermogravimetric analysis, density measurements, uniaxial deformation, Charpy impact testing, microhardness and dynamic mechanical thermal analysis. The morphological characterization has pointed out similar features that those already known and commonly found in annealed polyethylenes. ${ }^{3}$ However, thermogravimetric analysis,

\footnotetext{
${ }^{\dagger}$ To whom correspondence should be addressed (Phone: 34-91-5622900, Fax: 34-91-5644853, E-mail: ictcg26@fresno.csic.es).
} 
microscopy and dynamic mechanical behavior have provided the experimental support to explain the anomalous behavior observed in the impact tests.

\section{EXPERIMENTAL}

A commercially available HDPE with 1 -hexene as a comonomer in a content of $2 \%$ in weight was used. The HDPE under study was stabilized with phenolic and phosphonite antioxidants, whose CAS numbers are 6653-19-8 and 118578-01-1, respectively. Sheet specimens were obtained by compression molding according to standard procedure (ISO-1872-2) between hot plates at a temperature of $180^{\circ} \mathrm{C}$ at a pressure of $10 \mathrm{MPa}$ for 5 min. The thicknesses attained in such sheets were 3850 $\pm 50 \mu \mathrm{m}$.

A thermal annealing was imposed to the HDPE at $100^{\circ} \mathrm{C}$ for $500 \mathrm{~h}$ in an Heraeus VT-6060 oven under air atmosphere (ISO-188/ASTM-D 57 normalized test).

Wide-angle X-Ray diffraction patterns were recorded in the reflection mode at room temperature by using a Philips diffractometer with a Geiger counter connected to a computer. Ni-filtered $\mathrm{Cu}-K_{\alpha}$ radiation was used. The diffraction scans were collected over a period of 20 min. between $2 \theta$ values from 3 to 43 degrees, using a sampling rate of $1 \mathrm{~Hz}$. The goniometer was calibrated with a standard of silicon.

The crystalline diffractions and the amorphous component have been separated with a fitting program which allows to estimate the crystallinity of the samples. The baseline has been taken just as a straight line in the $2 \theta$ range from 8 to 37 degrees, and no further correction has been applied. The different diffraction peaks were fitted to Voigt functions. The amorphous peak of the different samples was found to be centered at about $2 \theta=20$ degrees, based on our previous work. ${ }^{4}$ The error in the crystallinity determinations, when these are expressed as percentage, is estimated to be \pm 5 units.

The samples were also studied by small-angle X-Ray scattering, SAXS, employing synchrotron radiation in the beamline A 2 at HASYLAB (Hamburg, Germany). The linear position-sensitive detector, at a distance of $235 \mathrm{~cm}$ from the sample, was calibrated with the different orders of the long spacing of rat-tail cornea $(\mathrm{L}=650$ A).

Density measurements were carried out in a hydrostatic balance and instruments SD-120 L according to the standard test (ISO 1183) at $23 \pm 1^{\circ} \mathrm{C}$ in distilled water.

Calorimetric analyses were carried out in a MettlerToledo DSC-821 calorimeter, connected to a cooling system and calibrated with different standards. The sample weights ranged from 5 to $10 \mathrm{mg}$, and the heating rate was $10^{\circ} \mathrm{C} \mathrm{min}-1$. For crystallinity determinations, a value of $290 \mathrm{~J} \mathrm{~g}^{-1}$ has been taken as the enthalpy of fusion of a perfectly crystalline material. ${ }^{5}$

A Jobin Yvon Ramanor U 1000 double monochromator, equipped with two $1800 \mathrm{~g} \mathrm{~mm}^{-1}$ planar holographic gratins, was used to acquire the Raman spectra. Excitation was provided by the $514.5 \mathrm{~nm}$ radiation of a Spectra Physics series $2000 \mathrm{Ar}^{+}$laser.

The tensile properties (elastic modulus, yield stress and elongation at break) were obtained following the
ISO 527 standard test. Dumb-bell shaped specimens with gauge dimensions $150 \mathrm{~mm}$ in length and $10 \mathrm{~mm}$ in width were punched out from the sheets. Specimens thickness was about $2 \mathrm{~mm}$ (ISO 1BA test specimens). Tensile testing was carried out using an Instron Universal 4522 testing machine calibrated according to standard procedures. The crosshead speed used was $50 \mathrm{~mm}$ $\min ^{-1}$ at room temperature.

The impact Charpy Notched tests were carried out in a CEAST 6545 pendulum machine (standard test given by ISO-179) at two different temperatures: -30 and $23^{\circ} \mathrm{C}$. The specimens utilized were $80 \mathrm{~mm}$ in length, 10 $\mathrm{mm}$ in width, $4 \mathrm{~mm}$ in thickness and a notched radius of $0.25 \mathrm{~mm}$ ).

A Vickers indentor attached to a Leitz microhardness tester was used to carry out microindentation measurements. Measurements were undertaken at room temperature $\left(23^{\circ} \mathrm{C}\right)$. A contact load of $0.98 \mathrm{~N}$ and a contact time of $25 \mathrm{~s}$ were employed. Microhardness, $M H$, values (in $\mathrm{MPa}$ ) were calculated according to the relationship:

$$
M H=2 \sin 68^{\circ} P / d^{2}
$$

A thermal stability analysis of the as molded and annealed specimens has been carried out in a Perkin-Elmer TGA7, calibrated according to a standard protocol. The sample weights were about $6 \mathrm{mg}$, and the heating rate was $10^{\circ} \mathrm{C} \min ^{-1}$.

SEM experiments were performed with a Philips XL 30-CP to study the surface morphology of the either original or annealed specimens. Samples were first fracture in liquid nitrogen, then sputter-coated with a thin layer of gold and finally analyzed under the microscope with an acceleration voltage of $20 \mathrm{kV}$.

Viscoelastic properties were measured with a Polymer Laboratories MK II dynamic mechanical thermal analyzer working in a tensile mode. The complex modulus and the loss tangent $(\tan \delta)$ of each sample were determined at $1,3,10$, and $30 \mathrm{~Hz}$ over a temperature range from -150 to $150^{\circ} \mathrm{C}$, at a heating rate of $1.5^{\circ} \mathrm{C} \mathrm{min}{ }^{-1}$. The apparent activation energy values were calculated according to an Arrhenius-type equation, employing an accuracy of $1^{\circ} \mathrm{C}$ in the temperature assignment of loss modulus maxima.

\section{RESULTS AND DISCUSSION}

Polyethylene, under usual conditions, crystallizes in an orthorhombic lattice as depicted in Figure 1 and described previously. ${ }^{6}$ It is viewed that the thermal annealing for a long time does not influence the type of crystal formed (Figure 1). A small shift of the (110), (200), and (020) diffractions to higher angles is observed due to the annealing. Consequently, the annealed specimen displays lower spacings than the as molded one because of a slightly greater perfection of crystallites in the former thermal treated specimen. The lattice constants, determined from the spacings, are higher in the original specimen as exhibited in Table I. Once these two axes are known, the density of the corresponding crystal can be calculated. It has been assumed a value of $2.54 \AA$ for the $c$ axis (fiber axis). Table I shows that as molded specimen exhibit crystals less compact than those found 


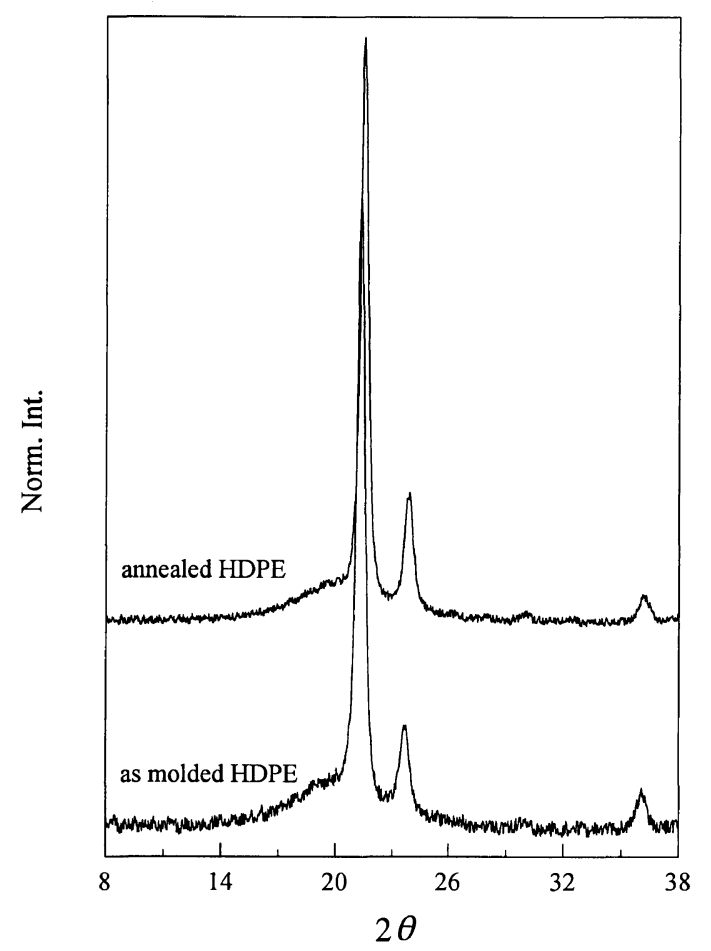

Figure 1. X-Ray diffraction patterns in as molded and annealed specimens.

Table I. Melt flow rate, overall density, crystalline reflection spacings $(d)$, lattice constants $(a, b, c)$, density of the crystal $\left(d_{\mathrm{C}}\right)$, mean crystal size for the (200) reflection $\left(L_{200}\right)$, melting temperature $\left(T_{\mathrm{m}}\right)$, melting enthalpy $\left(\Delta H_{\mathrm{m}}\right)$ and crystallinities deduced from density, X-Ray diffractograms, calorimetric, and Raman measure-

\begin{tabular}{|c|c|c|}
\hline $\begin{array}{l}\text { ments }\left(f_{\mathrm{c}}^{\text {acensity }}\right. \\
\text { Property }\end{array}$ & $\frac{f_{c}{ }^{D S c}, c}{H D P E}$ & \\
\hline Melt flow rate $(\mathrm{g} / 10 \mathrm{~min})$ & 3.34 & 3.60 \\
\hline Density / $\mathrm{g} \mathrm{cm}^{-3}$ & 0.945 & 0.949 \\
\hline$f_{\mathrm{c}}^{\text {density }}$ & 0.63 & 0.65 \\
\hline$d_{110}$ & 4.16 & 4.13 \\
\hline$d_{200}$ & 3.75 & 3.72 \\
\hline$d_{020}$ & 2.49 & 2.48 \\
\hline$a / \AA$ & 7.51 & 7.44 \\
\hline$b / \AA$ & 4.99 & 4.96 \\
\hline$c / \AA$ & 2.54 & 2.54 \\
\hline$d_{\mathrm{C}} / \mathrm{g} \mathrm{cm}^{-3}$ & 0.980 & 0.994 \\
\hline$f_{\mathrm{C}}^{\mathrm{WAXD}}$ & 0.72 & 0.75 \\
\hline$L_{200} / \AA$ & 147 & 156 \\
\hline$L^{\mathrm{SAXS}} / \mathrm{nm}$ & 23.8 & 25.2 \\
\hline Melting temperature $/{ }^{\circ} \mathrm{C}$ & 131 & 134 \\
\hline Melting enthalpy / $\mathrm{J} \mathrm{g}^{-1}$ & 180 & 183 \\
\hline$f_{\mathrm{c}}^{\mathrm{DSC}}$ & 0.62 & 0.63 \\
\hline$f_{\mathrm{c}}^{\mathrm{c}}$ Raman & 0.72 & 0.74 \\
\hline
\end{tabular}

$f_{c}$ has been estimated considering 0.853 and $1.000 \mathrm{~g} \mathrm{~cm}$
the density of perfect amorphous and crystalline polyethylene, respectively.

in the annealed sample, as effect of the remaining time $(500 \mathrm{~h})$ at $100^{\circ} \mathrm{C}$. Moreover, the different crystalline diffractions are slightly broadened in the initial specimen indicating its lower crystal size. In the current case, a mean crystal size for the (200) reflection has been estimated with the Scherrer's ${ }^{7}$ equation:

$$
L_{200}=\frac{K \cdot \lambda}{\beta_{0} \cdot \cos \theta}
$$

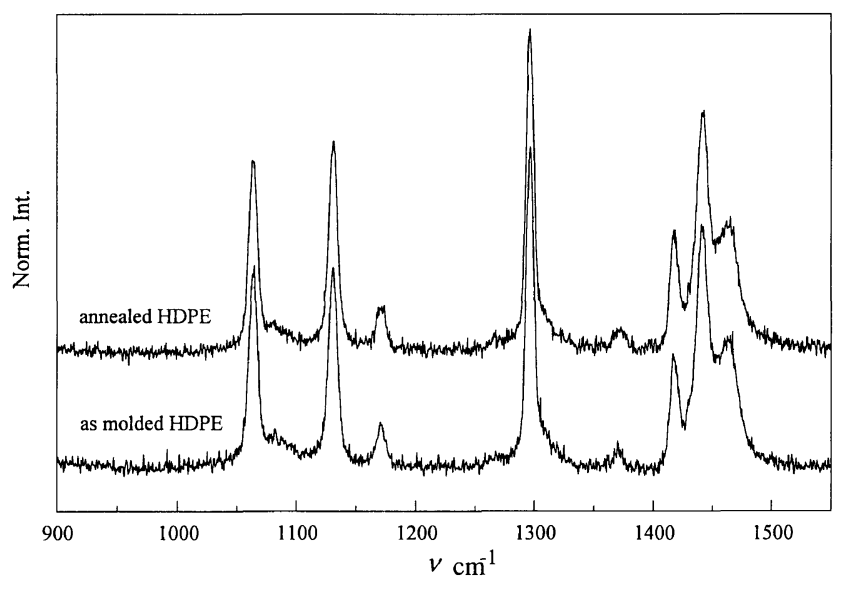

Figure 2. Raman spectra in as molded and annealed specimens.

where $L_{200}$ is the mean dimension of the crystallites perpendicular to the planes (200), $\beta_{0}$ is the integral breadth at half-maximum intensity of the pure reflection profile, and $K$ is a constant that has been assigned to be 0.94 . The crystallite size is slightly higher in the annealed than in the original specimen as seen in Table I. SAXS measurements confirm the results obtained by using Scherrer's equation. A slightly higher long spacing is found in the annealed specimen, as reported in Table I.

The separation of the X-Ray patterns into the either crystalline or amorphous contributions has allowed to estimate the crystallinity being slightly higher in the specimen thermally treated for $500 \mathrm{~h}$ at $100^{\circ} \mathrm{C}$. This parameter has been also obtained from density, calorimetric measurements, and Raman spectroscopy. The Raman spectra corresponding to the two samples are shown in Figure 2. They have been normalized to the same total area in the displayed region. The crystallinity has been estimated from the band at $1416 \mathrm{~cm}^{-1}$ in the Raman spectra. ${ }^{8}$ As exhibited in Table I, the differences in crystallinity found between both specimens are really small independently of the technique used. Annealing has changed the crystalline structure of the polyethylene under study but not in a significant fashion. In the annealed specimen, crystallinity is slightly higher and crystallites are denser and larger as just mentioned in $\mathrm{X}$-Ray diffraction analysis. These results are in a complete agreement with the higher melting temperature found in the thermal treated sample, as seen in Table I.

The morphological aspects just discussed show the expected behavior in the crystalline regions as effect of annealing. ${ }^{3}$ Consequently, these results point out that the uncommon enhance of the impact resistance described below do not directly involve the crystalline phase.

The mechanical parameters should be also expected to practically remain unaltered or change exclusively a little bit since the slight perfection of crystalline phase introduced by the annealing. This feature has been found in the either tensile properties or microhardness, as exhibited in Table II. Nevertheless, the impact behavior does show an anomalous tendency. At $-30^{\circ} \mathrm{C}$, the value provided by the Charpy Notched test is higher in the annealed specimen than that found in the original one whereas such a parameter is much more higher at room temperature for the former sample (Table II). These fea- 
Table II. Mechanical parameters of either original or annealed HDPE and the corresponding standard protocol followed during tests

\begin{tabular}{lrrc}
\hline \multicolumn{1}{c}{ Property } & HDPE & $\begin{array}{r}\text { HDPE- } \\
\text { ANN }\end{array}$ & $\begin{array}{c}\text { Standard } \\
\text { protocol }\end{array}$ \\
\hline Tensile modulus / $\mathrm{MPa}$ & 890 & & ISO-527 \\
Yield stress / $\mathrm{MPa}$ & 22 & 23 & ISO-527 \\
Elongation at break & 750 & 785 & ISO-527 \\
Charpy Notched at $-30^{\circ}{\mathrm{C} / \mathrm{kJ} \mathrm{m}^{-2}}^{-2}$ & 25 & 47 & ISO-179 \\
Charpy Notched at $23^{\circ} \mathrm{C} / \mathrm{kJ} \mathrm{m}^{-2}$ & 28 & 90 & ISO-179 \\
$M H^{\mathrm{a}} / \mathrm{MPa}$ & 44 & 44 & - \\
\hline
\end{tabular}

${ }^{\mathrm{a}} \mathrm{MH}:$ microhardness.

tures have been also found in other commercial polyethylenes with similar characteristics. ${ }^{9}$ More perfect crystallites usually confer brittleness to the material due to the higher strains imposed on the amorphous phase and to the stress concentrations produced by crystallites. ${ }^{3}$

A thermogravimetric analysis was performed to try to get additional information that justifies that unusual higher impact strength observed in the annealed specimen. Figure 3 shows that the thermal stability of the as molded specimens has been reduced as consequence of the long annealing at $100^{\circ} \mathrm{C}$ in an oven. The stability is similar for both specimens up to around $275^{\circ} \mathrm{C}$, but after this temperature the annealed sample exhibits a secondary step in lost weight, about $6 \%$, before the main degradation process. In polypropylene thermally aged at $90^{\circ} \mathrm{C}$ in an oven, a definite etching effect on the surface has been described. ${ }^{10}$ Consequently, the loss of weight of $6 \%$ in the annealed polyethylene under study might be owed to the volatilization of low-molecular weight oxidation products caused by specimen exposure for a long time at $100^{\circ} \mathrm{C}$, similarly to what occurs in polypropylene. There is an apparent induction time which is different depending upon the structure of the material. During that induction time, the oxidation products do not affect the macroscopic properties. Once that time is concluded, the whole properties of the polymer decrease catastrophycally. ${ }^{11}$ In the annealed polyethylene investigated, such an induction time seems to have not been completed since either mechanical or thermal properties are preserved or even slightly enhanced due to the small perfection in the crystallites. The long exposure at $100^{\circ} \mathrm{C}$ seems to have provoked crazes on the surfaces by the action of those oxidation products detected by thermogravimetric analysis. Such crazes are the responsible for the improvement in the impact strength of the annealed specimen. Figure 4 depicts the bulk morphology of the specimens under study as revealed by fracture at liquid nitrogen temperatures. This figure clearly shows a more homogeneous fracture surface in the annealed material than that found in the polymer before thermal treatment at $100^{\circ} \mathrm{C}$. Such a homogeneous surface is related to the improved impact resistance exhibited in the annealed sample.

To understand these sometimes contradictory effects of crazing on fracture properties, it has to be said that crazes, unlike cracks, are load bearing because their two surfaces are bridged by many small fibrils with diameters in the range 5 to $30 \mathrm{~nm} .{ }^{11}$ When true cracks form, however, they do so by breakdown of the fibril structure within a craze, a process which is added by the high local

Polym. J., Vol. 33, No. 3, 2001

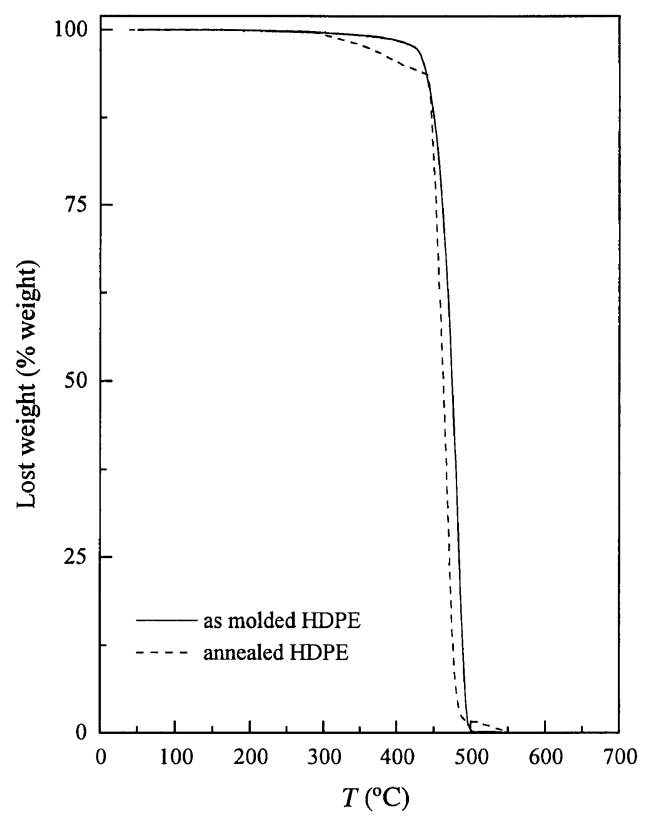

Figure 3. Thermogravimetric plots in as molded and annealed specimens.

a)

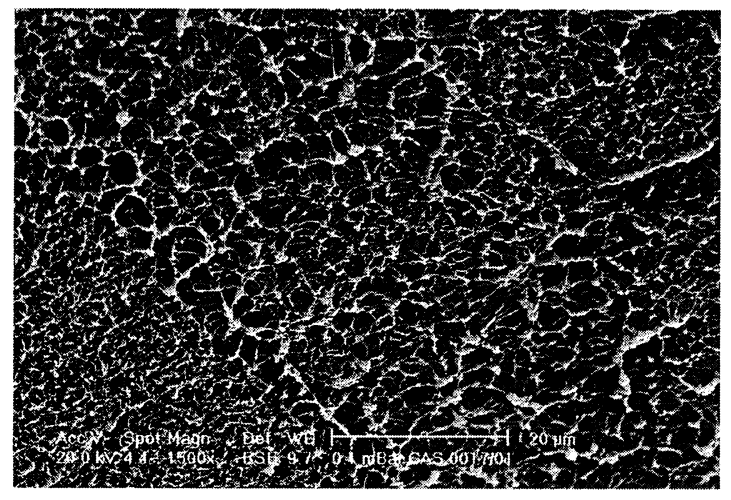

b)

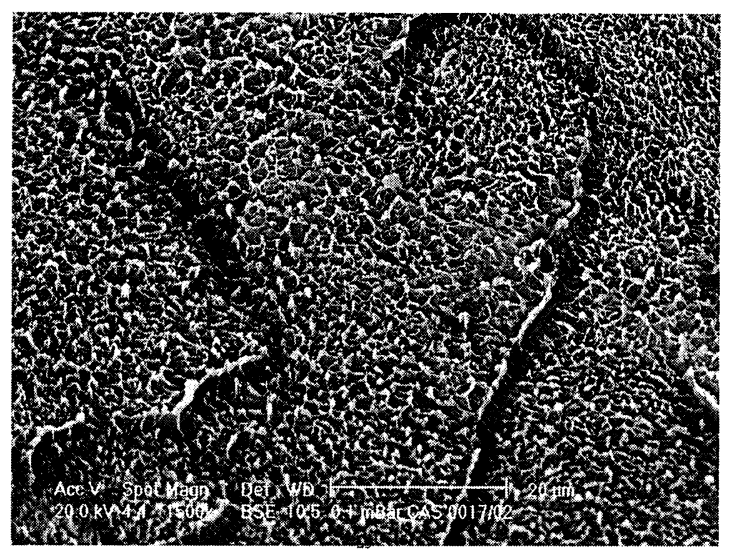

Figure 4. Fracture surface of specimens: a) as molded, b) annealed at $100^{\circ} \mathrm{C}$ for $500 \mathrm{~h}$.

stresses in the fibrils. Hence to control crack nucleation one must stop craze formation or make it more difficult relative to the shear deformation. Nevertheless under 
certain conditions crazing can be beneficial. Crazing is a process of plastic deformation and as such is the most important source of fracture toughness in polymer which deforms by crazing rather than shear. By arranging that very high densities of crazes nucleate and grow before these crazes break down to form cracks, substantial macroscopic plastic strains due to crazing can be achieved. The improved impact toughness observed in the annealed polyethylene under study, where the oxidation products seem to have created surface crazes, is an example of the exploitation of this positive aspect of crazing.

A supplementary information can be attained by dynamic mechanical analysis. Figure 5 shows that storage modulus is higher in as molded specimens than in the annealed one over almost the whole temperature range, though crystalline regions have been slightly enhanced in the latter sample, as indicated by its a bit higher melting temperature and the X-Ray measurements. Annealing for $500 \mathrm{~h}$ at $100^{\circ} \mathrm{C}$ has allowed that macromolecules relieve stress concentrations caused along the molding process. Therefore, $\mathrm{E}^{\prime}$ is lower for the annealed sample up to temperatures high enough where the slight higher perfection in crystalline phase plays a significant role in the viscoelastic properties, i.e., $110^{\circ} \mathrm{C}$, and the stress concentrations relief becomes secondary, as presented in Table III.

In $\tan \delta$ and loss modulus plots, three different relaxations are noticeable in both specimens. The $\gamma$ relaxation at approximately $-115^{\circ} \mathrm{C}$, the $\beta$ process in the -35 to $-20^{\circ} \mathrm{C}$ range, and the $\alpha$ relaxation centered at about $50^{\circ} \mathrm{C}$ (in $\mathrm{E}^{\prime \prime}$ basis at $3 \mathrm{~Hz}$ ). In polyethylene loss modulus data provide more exact information than $\tan \delta$ since relaxations (except that occurring at lowest temperatures) are less broad and the peak positions are better defined. Accordingly, data listed in Table IV are taken from $E^{\prime \prime}$ plots. Those data characterize the dynamic mechanical behavior of the investigated materials, such as temperature location and apparent activation energy of the different relaxations.

Loss moduli curves of polyethylene are well described as composed by contribution of different Gaussian curves, one for each observed relaxation process. Such a separation does not have a theoretical basis that can explain satisfactorily the shape of the dependence of loss modulus on temperature, though some factors that can influence it are known. A method of curve deconvolution to analyze the dynamic mechanical loss curves in the region of the glass transition of several polymers has been proposed $^{12}$ confirming the validity of this empirical approximation. In addition, it was shown that a Gaussian function provided the best fitting. In the present case, the summation of three Gaussian curves for the specimens used yields a very good overall fitting over the whole experimental range measured. This deconvolution is a very useful tool for the estimation of relative areas of the different relaxation mechanisms and for the assessment of $\beta$ and $\alpha$ relaxation location as the overlapping of both processes is very important, as in the current case.

The $\gamma$ relaxation in polyethylene was firstly attributed to crankshaft movements of polymethylenic chains. ${ }^{13}$ Though a lot of work concerning the $\gamma$ relaxation in poly-

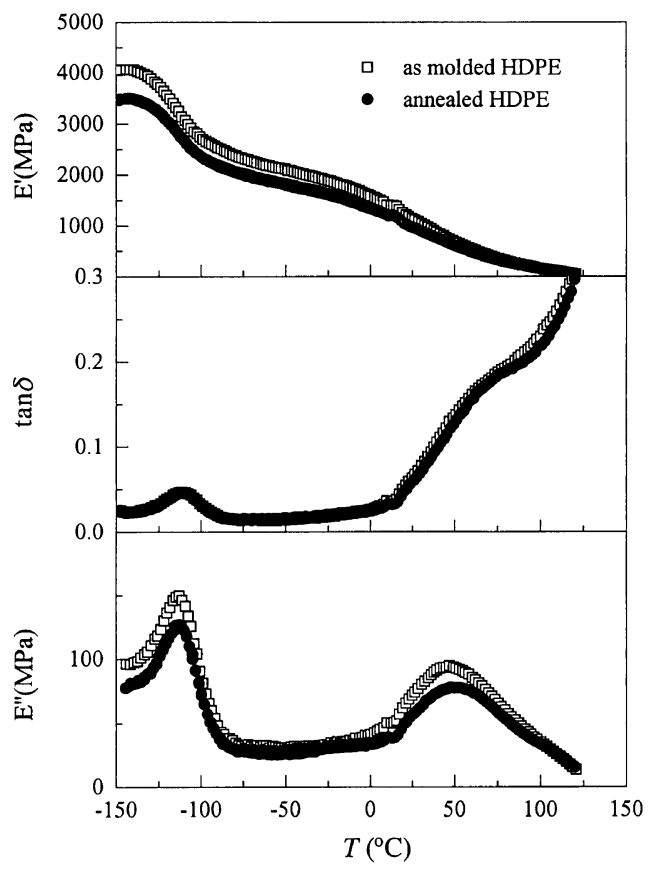

Figure 5. Temperature dependence of the complex modulus and loss tangent of as molded and annealed specimens.

Table III. Storage modulus (MPa) values at the relaxations temperatures and at temperatures in which no relaxation is taken place (at $3 \mathrm{~Hz}$ )

\begin{tabular}{ccc}
\hline Temperatures $/{ }^{\circ} \mathrm{C}$ & HDPE & HDPE-ANN \\
\hline-140 & 4050 & 3470 \\
-115 & 3320 & 2910 \\
-60 & 2175 & 1895 \\
-30 & 1935 & 1675 \\
0 & 1580 & 1325 \\
50 & 700 & 615 \\
110 & 90 & 105 \\
\hline
\end{tabular}

Table IV. Relaxation temperatures and activation energies for the different relaxation processes in the original and annealed

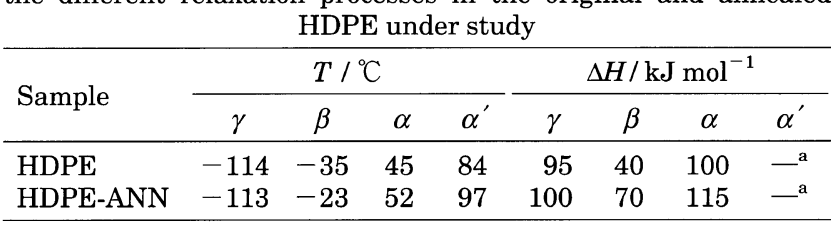

- ${ }^{\mathrm{a}}$ The relaxation process is not observed in all the frequencies.

ethylene has been done, there remains no clear consensus regarding the details of the underlying motional process. ${ }^{14,15}$ There is, however, a body of opinions which support one or more of the various model for restricted conformational transitions as kink formation, inversion and migration. ${ }^{13,16-18}$ This relaxation is shifted to slightly higher temperatures in the annealed specimen because of the slightly perfection in the crystallites. Such an improvement in the crystalline region might impose greater restrictions to the amorphous phase where this relaxation takes place. Consequently, the apparent activation energy of the $\gamma$ relaxation is a bit higher in the annealed specimen than in the as molded one, as detailed in Table IV. 
The $\beta$ relaxation has been universally detected in branched polyethylenes at temperatures around $-20^{\circ} \mathrm{C}$ but it sometimes appears, though weakly, in some samples of linear polyethylene. From the study of various polyethylenes and their copolymers, it has been concluded that this relaxation results from motions of chain units in the interfacial region. ${ }^{19,20}$ Figures 5 and 6 show that this $\beta$ relaxation process is more intense in the annealed specimen. Such a mechanism has a direct relationship with the higher impact properties already pointed out in that sample since the crazes caused during the annealing process have favored the interfacial content and the area of this relaxation has been increased as occurred with the impact strength since a more energy dissipation can be made in this temperature range through the crazes formed during the annealing process at $100^{\circ} \mathrm{C}$. The apparent activation energy associated to this process has been also raised considerably.

The $\alpha$ relaxation in polyethylene has been associated to vibrational and reorientational motions within the crystallites. $^{21,22}$ This crystalline relaxation is recognizable in both specimens under study. The intensity of this process is lowered in thermally aged specimen because of the greater restrictions imposed by the slightly better formed crystallites. Consequently, it is shifted to higher temperatures in that sample and its apparent activation energy is also higher. In addition, it is more clearly evident a shoulder occurring in the high temperature side, labeled as $\alpha^{\prime}$ relaxation, which origin is not very well established. A translational motion of chain segments along the chain axis within the crystal lattice has been propose $^{22}$ as cause of this relaxation. It might be more prominent in the annealed sample than in the as molded one since during the annealing time at $100^{\circ} \mathrm{C}$ some crystallites have become thicker and, the crystallite size distribution has been, consequently, broadened.

Summing up, the annealing at $100^{\circ} \mathrm{C}$ for $500 \mathrm{~h}$ in a commercial polyethylene has two, at first, main opposite effects: an expected slight perfection in crystallites and an unusual remarkable increase in impact properties. The annealing has provoked changes in the crystalline region that have been evaluated by X-Ray diffraction patterns (crystalline reflection spacings, lattice constants, density of the crystal, mean crystal size for the (200) reflection and crystallinity), calorimetric measurements (higher melting temperature and crystallinity in the annealed specimen), Raman spectroscopy and density measurements (crystallinity). Moreover, annealing is responsible for a considerable enhance in the impact strength due to the crazes formation during the annealing time at $100^{\circ} \mathrm{C}$. Such a time has not been long enough to go beyond the apparent induction period for thermal aging in this material since the rest of mechanical parameters, such as Young's modulus, breaking elongation, are unchanged. A diminishment of thermal stability has been observed by thermogravimetric analysis in the annealed sample. It might be due to the volatilization of low-molecular weight oxidation products which have caused the crazes within the material structure. As consequence of that crazes formation, the $\beta$ relaxation has been significantly enlarged allowing a higher dissipation of energy in the temperature range of interest.

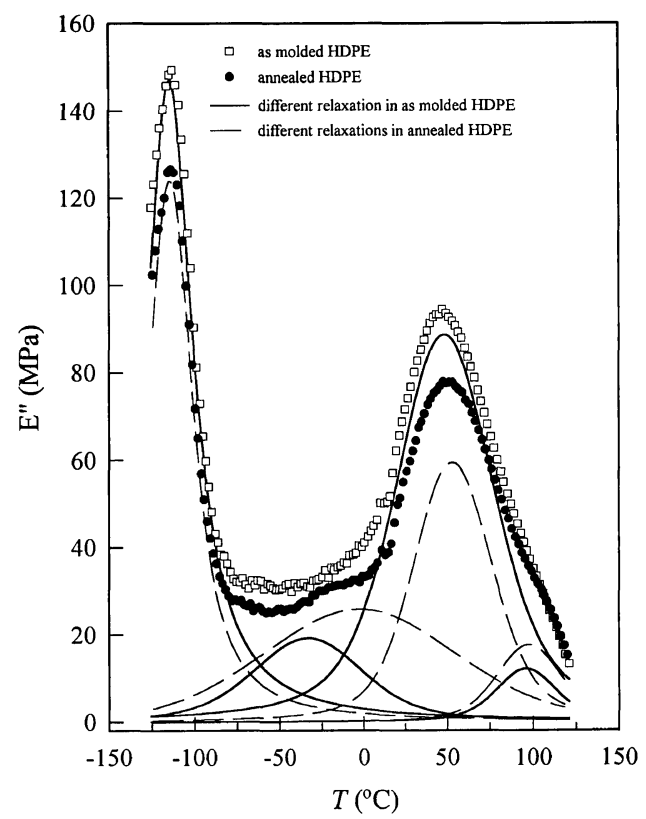

Figure 6. Separation of the global viscoelastic response in terms of the Loss Modulus ( $\left.\mathrm{E}^{\prime \prime}\right)$ into the different relaxation processes in as molded and annealed specimens.

Annealing has allowed the relief of stress concentrations caused along the processing as shown the analysis of storage modulus values. Consequently, annealing has provoked an increase in the dimensional stability of this material. From a practical point of view, all the mentioned features suggest a similar thermal annealing to containers for transportation and storage of either oils or dangerous substances to enhance the impact resistance since the impact strength is a very critical parameter in this particular application.

Acknowledgments. Th authors would like to thank at Repsol-YPF Área Operativa Química (LATD) to Ms. B. Soop, M. L. Astudillo, J. A. Ruano for the differential scanning calorimetry, density, stress- ${ }^{-}$strain and impact experiments; to F. J. Gómez for the SEM measurements; and at Instituto de Ciencia y Tecnología de Polímeros to S. Moñivas for providing machined specimens which were used for the X-Ray, Raman spectroscopy, dynamic mechanical, thermogravimetric and microhardness measurements. The synchrotron work (in the polymer line of Hasylab at DESY, Hamburg) was supported by the IHP Programme "Access to Research Infrastructures" of the European Commission (Contract HPRI-CT1999-00040). We thank the collaboration of the Hasylab personnel, and specially Dr. A. Meyer, responsible of the polymer beamline.

\section{REFERENCES}

1. J. Stěpek, V. Ducháček, D. Čurda, J. HoráČek and M. Sípek, "Polymers as Materials for Packaging", Ellis Horwood Limited, Chichester, UK, 1987, chapter 1, pp 17-111.

2. D. V. Rosato, "Blow Molding Handbook", Hanger, New York, N.Y., 1989, p 738.

3. L. E. Nielsen and R. F. Landel, "Mechanical Properties of Polymers and Composites", 2nd ed, Marcel Dekker, New York, N.Y., 1994, chapter 4, pp 131-233. 
4. M. L. Cerrada, R. Benavente, B. Peña, and E. Pérez, Polymer, 41, 5957 (2000).

5. B. Wunderlich, "Macromolecular Physics", Academic Press, New York, N.Y., 1980, vol. 3, p 42.

6. D. C. McFaddin, K. E. Russel, G. Wy, and R. D. Heyding, $J$. Polym. Sci., Part B: Polym. Phys., 31, 175 (1993)

7. L. E. Alexander, "X-Ray Diffraction Methods in Polymer Science", John Wiley \& Sons Ltd., New York, N.Y., 1969, ch. 7, p 423.

8. G. R. Strobl and W. Hagedorn, J. Polym. Sci., Part B: Polym. Phys., 16, 1181 (1978).

9. C. Sierra (unpublished data).

10. M. G. Wyzgoski, J. Appl. Polym. Sci., 26, 1689 (1981).

11. K. Friedrich, Adv. Polym. Sci., 52/53, 225 (1983).

12. G. Rotter and H. Ishida, Macromolecules, 25, 2170 (1992).
13. T. F. Shatzki, J. Polym. Sci., 57, 496 (1962).

14. R. G. C. Arridge, Rev. Deform. Behav. Mater., 3, 249 (1981).

15. R. H. Boyd, Polymer, 26, 1123 (1985).

16. R. F. Boyer, Rubber Chem. Technol., 36, 1303 (1963).

17. R. H. Boyd and R. S. Breitling, Macromolecules, 7, 855 (1974).

18. R. H. Boyd, J. Polym. Sci., Part B: Polym. Phys., 13, 2345 (1975).

19. R. Popli and L. Mandelkern, Polymer Bull., 9, 260 (1983).

20. R. Popli, M. Glotin, L. Mandelkern, and R. S. Benson, J. Polym. Sci., Part B: Polym. Phys., 22, 407 (1984).

21. N. G. McCrum, B. E. Read, and G. Williams, "Anelastic and Dielectric Effects in Polymeric Solids", Dover Publication, New York, N.Y., 1991, p 358.

22. I. M. Ward, "Mechanical Properties of Solids Polymers", 2nd ed., John Wiley \& Sons Ltd., Chischester, UK, 1985, ch. 8. 